\title{
Evaluation of the orthopedic residency training program in Saudi Arabia and comparison with a selected Canadian residency program
}

This article was published in the following Dove Press journal:

Advances in Medical Education and Practice

19 September 2014

Number of times this article has been viewed

\author{
Abdulaziz Al-Ahaideb' \\ Hamza M Alrabai' \\ Osama A Alrehaili' \\ Abdulaziz N Aljurayyan' \\ Ranyah M Alsaif ${ }^{2}$ \\ Nizar Algarni' \\ Hazem M Al-Khawashki' \\ Abdulrahman D Algarni' \\ 'Department of Orthopedics, \\ ${ }^{2}$ Department of Physiotherapy, King \\ Khalid University Hospital, King Saud \\ University, Riyadh, Saudi Arabia
}

Objective: The primary aim of the present study was to assess the quality of the Saudi Orthopedic Residency Program.

Methodology: As a comparator, a cross-sectional survey involving 76 Saudi residents from different training centers in Saudi Arabia namely; Riyadh, Jeddah, Medina, Abha, and Dammam and 15 Canadian.

Results: The results showed that Canadian residents read more peer-reviewed, scholarly articles compared with Saudi residents $(P=0.002)$. The primary surgical role for residents was to hold retractors during surgery. The survey respondents strongly supported the ability to recommend removal of incompetent trainers. Saudi trainees were more apprehensive of examinations than Canadian trainees $(P<0.0001)$. Most residents preferred studying multiple-choice questions before examinations. Saudi and Canadian participants considered their programs to be overcrowded. Unlike Canadian participants, Saudi trainees reported an inadequate level of training $(P<0.0001)$.

Conclusion: Educational resources should be readily accessible and a mentorship system monitoring residents' progress should be developed. The role of the resident must be clearly defined and resident feedback should not be ignored. Given the importance of mastering basic orthopedic operative skills for residents, meaningful remedial action should be taken with incompetent trainers.

Keywords: evaluation, medical education, orthopedic board, residency program, training

\section{Introduction}

The Saudi Orthopedic Residency Program, under the supervision of the Saudi Commission for Heath Specialties, is the authority that conducts and monitors the training process of orthopedic residents in Saudi Arabia. Each trainee must complete at least 5 years of training, during which the resident is subject to annual examinations and cyclic evaluations. After passing the final exam, which includes theoretical and clinical components, candidates are granted the Saudi Board of Orthopedics certificate. The Saudi Orthopedic Residency Program has developed over time. Recently, the number of trainees has increased dramatically and more training centers have been established in major cities across the kingdom. These major developments have had both negative and positive impacts on the status of current residents.

The relative variability among residency training programs worldwide has been primarily due to the lack of standardization of educational content. ${ }^{1}$ The competency of a training program is reflected by the level of competency of its trainees. The objective of the present study was to examine the attitudes and opinions of residents toward the Saudi Orthopedic Residency Program and to elaborate on the program's
Correspondence: Hamza M Alrabai Department of Orthopedics (49), King Khalid University Hospital, King Saud University, PO Box 7805, Riyadh I 1472, Saudi Arabia Tel +966 || 467087 | $\mathrm{Fax}+966$ II 4679436

Email hamzarabai@gmail.com 
strengths and weaknesses. In addition, our study included a comparison of the Saudi program with the McGill University Orthopedic Residency Program in Montreal, QC, Canada. ${ }^{2}$ The latter has been approved by the Royal College and the Collège des Médecins du Québec, and meets the requirements of the American Board of Orthopedic Surgery.

The role of contemporary medical education is crucial; therefore, the development of health care systems through which medical education can be enhanced effectively has received more attention. For example, in 1996, the Royal College of Physicians and Surgeons of Canada implemented guidelines of the Canadian Medical Education Directions for Specialists. ${ }^{3}$ In addition, the United States applied the regulations of the Accreditation Council for Graduate Medical Education (ACGME) in 1999.4-6 Similarly, the Australian Curriculum Framework for Junior Doctors was adopted in Australia in 2006.,8 Such regulations are of considerable help to decision makers who oversee higher-education organizations in various disciplines as they attempt to improve the value of their programs by reinforcing positive aspects and mitigating the impact of or eliminating negative issues. To our knowledge, there is no study that has examined the Saudi Orthopedic Residency Program from the residents' perspective.

\section{Methods}

Following approval of the project from the institutional review board, a cross-sectional study examining the period from 2011 to 2012 was performed. It was conducted among residents training in the Saudi Orthopedic Residency Program in Riyadh, Jeddah, Dammam, Medina, and Abha, as well as residents in the McGill University Orthopedic Residency Program in Canada. The Saudi sample consisted of 76 residents, while the Canadian sample consisted of 15 residents. Junior residents who were in their initial 2 years of training were excluded because of their inadequate length of orthopedic practice.

The Saudi trainees were invited to participate in the survey electronically through email, whereas hard-copy questionnaires were completed by the Canadian participants. Out of the 90 Saudi-trained residents invited, 76 residents participated in the survey, with approximately an $84 \%$ response rate. On the other hand, 15 questionnaires were completed out of 20 questionnaires distributed among the McGill University residents, with a response rate of $75 \%$. The questionnaire was carefully designed to address the most important issues of the training programs. It consisted of 28 items arranged in six sections including demographic data, academic teaching, surgical training, teaching staff efficiency, exams, and residents' competency.

The collected data were analyzed using SPSS version 19 (IBM Corporation, Armonk, NY, USA). A test-retest study was performed to confirm the survey's reliability. $P$-values were calculated using $\chi^{2}$ and Fisher's exact tests; $P<0.05$ was considered to be statistically significant.

\section{Results}

The Canadian and Saudi samples had comparable male-to-female ratios, and the participants were evenly distributed with regard to years of training. Together, Saudi and Canadian responses revealed that textbooks were the main source of specialty information, followed by peerreviewed scholarly articles and, finally, by scientific discussion among staff. However, Canadian-trained residents tended to read scholarly articles more frequently $(46.7 \%)$ than their Saudi-trained counterparts $(10.5 \%)(P=0.002)$. Trauma rounds were considered to be regular daily to weekly events by the majority of Saudi and Canadian residents, who rated such activities as good to excellent. In addition, according to most of the trainees, assigning a specific mentor to oversee trauma rounds was the best way to ensure maximum benefit, rather than increasing their number or duration. Most of the Saudi and Canadian respondents stated that they attended a half-day activity on a regular basis to obtain benefit. Although the majority of the residents were in agreement with regard to its benefit, they differed on the proper way to conduct this activity. More than half of the Canadian participants believed that the tutor should be more interactive and fully prepared. On the other hand, nearly half of Saudi residents favored case discussions rather than didactic subject presentations.

The survey demonstrated that $40 \%$ of Canadian attending physicians regularly discussed all cases in their clinics with the residents. This proportion, however, was dramatically lower among the Saudi consultants (5.3\%), a difference that was statistically significant $(P<0.0001)$. The tendencies to exclusively discuss new cases or selected advanced cases, usually requiring decisions by senior staff, were relatively comparable in both samples. Additionally, a minority of attending faculty members were not willing to discuss any clinical case with residents, which was not significantly different between the samples $(7.9 \%$ and $6.7 \%$ in Saudi and Canadian samples, respectively). Surprisingly, although not statistically significant, approximately $4 \%$ of Saudi participants stated that their consultants were physically absent from the clinic, whereas no similar absences were reported in Canada. Most of the participants from both 
groups indicated that their primary role in the operating theater was no more than that of "retractor holder". Closure of the operative site was the second most common surgical task assigned to residents. Occasionally, a few residents were offered the opportunity to operate as a primary surgeon. Each participant rated some orthopedic subspecialties that he or she experienced the best and worst surgical training, as shown in Figures 1 and 2, respectively. Table 1 summarizes the adequacy of surgical exposure with regard to the basic orthopedic surgical interventions.

More than $80 \%$ of the residents in Saudi Arabia and Canada strongly agreed that the program committee should have the authority to restrict incompetent, unprofessional attending physicians from teaching. According to $>60 \%$ of the Saudi and Canadian responses, only $75 \%$ of the current training consultants are sufficiently competent with regard to their training of residents. Almost all of the residents concurred on the right to evaluate training consultants and, subsequently, to participate in decisions regarding restricting or eliminating the participation of nonefficient trainers based on the residents' evaluation. Survey respondents believed that the most effective ways to encourage consultants to perform their best in terms of resident teaching was to suspend residency service in case of shortcomings, followed by financial disincentives and, finally, by removal of academic title privileges.

Exams were the major source of stress for $86 \%$ of the Saudi trainees compared with $40 \%$ of the Canadian trainees $(P<0.0001)$. Although mock exams are a well-established way to prepare candidates, almost $70 \%$ of Saudi residents claimed that they have never been involved in such an exam, compared with approximately $10 \%$ of the Canadian trainees $(P<0.001)$.
Interestingly, it appeared that $>80 \%$ of the Saudi and Canadian residents believed that exam scores had no relationship with the resident's actual level of competency. The majority of the Saudi and Canadian responses agreed that examination-driven reading has expanded at the expense of reading for clinical practice; however, the Saudi participants showed more assertiveness on this matter $(P<0.0001)$. Notably, in both countries, the residents showed increasing tendency toward studying multiple-choice questions during exam preparation. Textbooks were considered to be the second most popular source of information, followed by scholarly articles.

There was clear consensus among Canadian participants that their program was oversaturated with residents. In accord, almost half of the Saudi participants, particularly in the capital city of Riyadh, believed that the number of residents exceeded the program's capacity. Most of the Saudi respondents agreed that their training was inadequate, which, consequently, made them less competent surgeons. In contrast, the majority of their Canadian counterparts rejected such a statement $(P<0.0001)$. Approximately half of the Saudi residents felt comfortable performing general orthopedic operations independently, without senior supervision. The Canadian-trained residents reported more independence - up to $80 \%$ - in terms of performing general orthopedic surgeries alone.

\section{Discussion}

For centuries, it was unusual to encounter a student who did not have a textbook. In fact, textbooks were the leading educational resource for the bulk of orthopedic residents all over the globe. However, the recent trend toward reading more scholarly articles cannot be denied. It appears that Canadian residents were more interested in this than Saudi

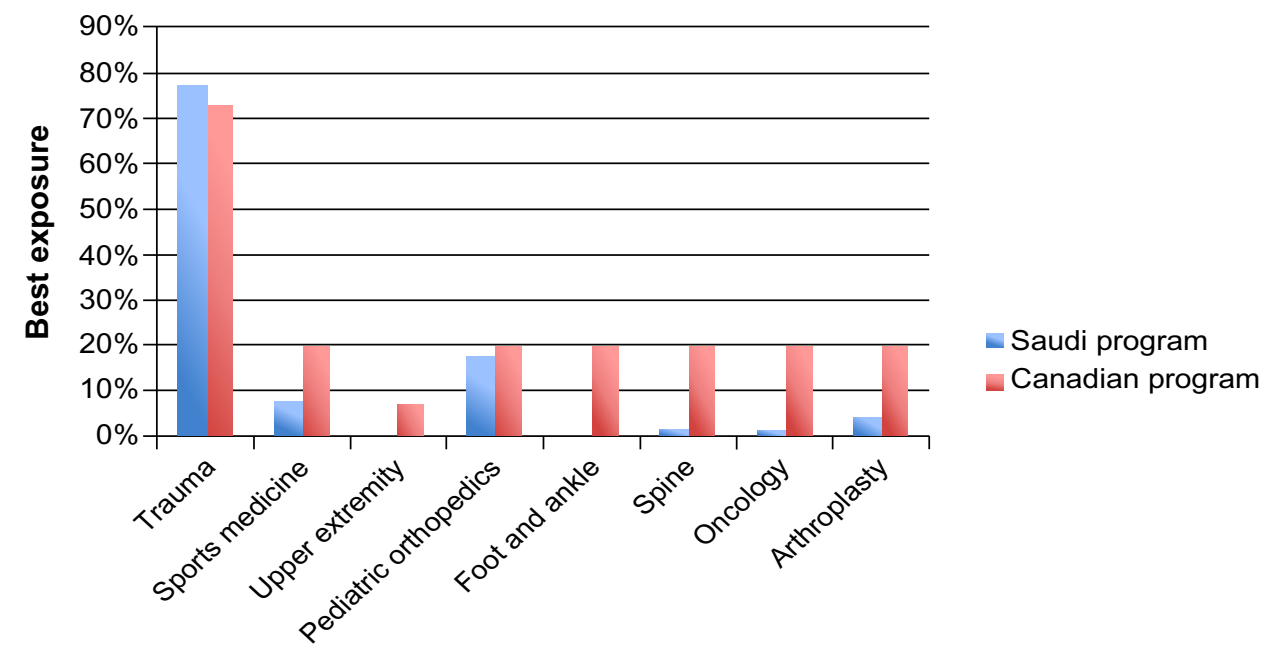

Figure I Best exposure to surgical training according to subspecialty. 


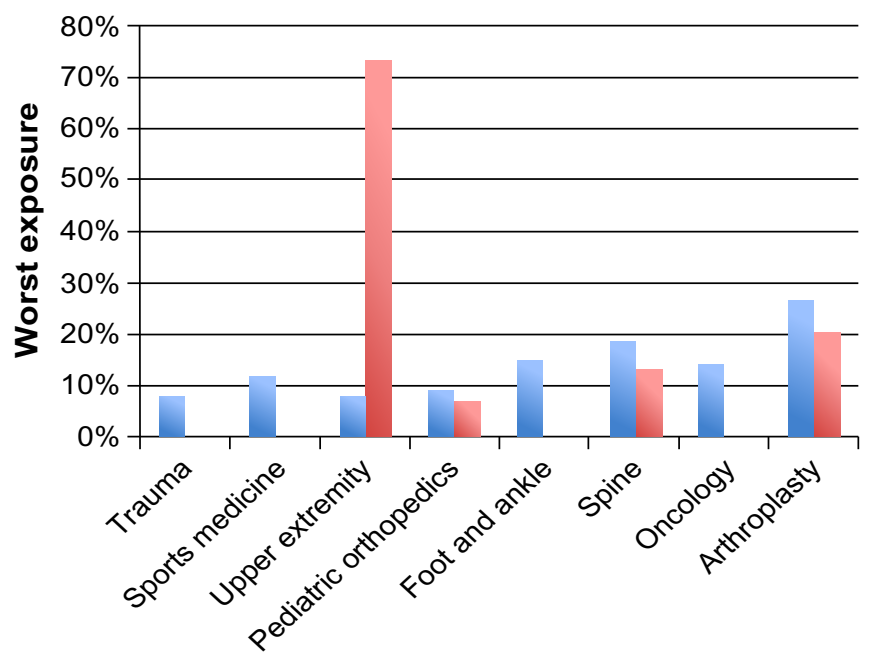

Saudi program

Canadian program

Figure 2 Worst exposure to surgical training according to subspecialty.

residents, likely due to contemporary changes in medical education methodology. Many authors have emphasized the considerable educational value of scholarly articles. ${ }^{9-11}$ Scholarly articles currently form the basis of various educational fields such as treatment guidelines, classifications, surgical approaches, and journal clubs. In addition, the fact that scholarly articles are a rich source of examination questions makes them a more attractive study material for residents. Unfortunately, high-value articles are not easily accessible to all. The majority of training institutes in Saudi Arabia do not provide residents with free access to reputable orthopedic journals. These barriers may factor into the lower use of scholarly articles by Saudi trainees. Assigning a specific mentor for trauma rounds was highly rated by most of the trainees rather than increasing their frequency or duration. The positive role of mentorship can be incorporated into training in multiple fields. Flint et al ${ }^{12}$ reported that $95 \%$ of surveyed residents requested mentorship as part of their training program.
Orthopedic outpatient clinics represent a rich resource of teaching cases. Residents' clinical judgment abilities and communication and technical skills are continuously refined in outpatient settings. ${ }^{13}$ It appears that Saudi orthopedic educators fall behind in terms of proper utilization of their clinic time to teach trainee clinicians. It is perplexing that the current system overlooks this phenomenon. Pinney et $\mathrm{a}^{14}$ emphasized the paramount role of teaching in the clinical setting and suggested the "One-Minute Preceptor" approach to maximize the resident's benefit from clinical teaching. Briefly, this approach consists of two stages: first, the resident performs the preliminary assessment of the patient; subsequently, the attending physician supports the resident's correct assessments and corrects the mistakes while evaluating the patient. The data showed that Canadian and Saudi trainees experienced their greatest surgical exposure in the trauma discipline. Such findings are expected and may be due to the high incidence of trauma-related morbidities. Residents in Canada

Table I Adequacy of surgical exposure in selected basic orthopedic operations

\begin{tabular}{|c|c|c|c|c|c|}
\hline & \multicolumn{2}{|c|}{$\begin{array}{l}\text { Saudi program } \\
(n=76)\end{array}$} & \multicolumn{2}{|c|}{$\begin{array}{l}\text { Canadian program } \\
(n=15)\end{array}$} & \multirow[t]{2}{*}{$\mathbf{P}$} \\
\hline & Adequate & Inadequate & Adequate & Inadequate & \\
\hline Femur nailing & $47(70.1)$ & $20(29.9)$ & $14(93.3)$ & I (6.7) & $0.055^{*}$ \\
\hline ORIF of ankle fractures & $40(59.7)$ & $27(40.3)$ & $14(93.3)$ & I (6.7) & $0.013^{* *}$ \\
\hline DDH open reduction & $28(42.4)$ & $38(57.6)$ & $3(20)$ & $12(80)$ & $0.107^{* *}$ \\
\hline Knee arthroscopy and meniscectomy & $21(31.3)$ & $46(68.7)$ & $14(93.3)$ & I (6.7) & $0.0001 * *$ \\
\hline Shoulder arthroscopy & $9(13.4)$ & $58(86.6)$ & $6(40)$ & $9(60)$ & $0.026^{*}$ \\
\hline Primary total knee replacement & $27(4 I .5)$ & $38(58.5)$ & $14(93.3)$ & $\mathrm{I}(6.7)$ & $0.0001 * *$ \\
\hline Posterior spinal fusion and instrumentation & $26(38.8)$ & $41(61.2)$ & $10(66.7)$ & $5(33.3)$ & $0.049 * *$ \\
\hline Hallux valgus correction & $6(9.0)$ & 61 (9I.0) & $9(60)$ & $5(33.3)$ & $0.000 I^{*}$ \\
\hline
\end{tabular}

Notes: Data presented as $n(\%)$ unless otherwise indicated. *By Fisher's exact test; **by $\chi^{2}$ test.

Abbreviations: DDH, developmental dysplasia of the hip; ORIF, open reduction and internal fixation. 
and Saudi Arabia reported insufficient surgical training in upper extremity and arthroplasty fields, respectively. These deficiencies could be related to the paucity of qualified trainers in these subspecialties. Improving and maintaining operative technical skills require continuous practice. The trainee orthopedist follows a learning curve to master basic orthopedic procedures. It is the responsibility of the teaching surgeon to encourage the trainee to gain more surgical expertise and skills by practice. Robbins et $\mathrm{al}^{15}$ recommend defining a minimum target of surgical cases based on anatomical region and difficulty, as well as assigning a specific role to the resident in each procedure.

When residents are assigned to accredited training institutes each year, they help to perform the duties of their consultants without assessment of the consultants' teaching aptitude. The presence of incompetent teachers is an unfortunate reality in every educational program. Identifying and removing such inefficient teachers from the training program would lead to a healthier learning environment for trainees. Unfortunately, residents are not provided with the opportunity to evaluate faculty members in the Saudi program. The aforementioned points could explain why the Saudi program contains a higher number of uninterested consultants and portends that this figure may increase unless the situation is rectified. Wasting residents' time for one or more rotations with an uninterested consultant makes little sense and places the training process in jeopardy. Similarly, the adequacy of the 5-year orthopedic training period was the subject of debate in the US after restricting the residents' work hours by the ACGME. ${ }^{16}$ Furthermore, retaining nonefficient educators in training programs while restricting remedial intervention may have significant consequences. Medical education experts have proven the role of the "hidden curriculum" in adult learning. The concept of the hidden curriculum refers to the summation of the incompetent teacher's behaviors, attitudes, habits, and manners that could be indirectly and unconsciously acquired by the learner during contact with the teacher. ${ }^{5,17,18}$ A reward and punishment system can be implemented to improve orthopedic education. Active, competent educators should earn certain incentives, while delinquent teachers should be identified and penalized. Most residents elected to exclude inactive, incompetent educators from the residency service as the best way to enhance their educational productivity.

Exam-related anxiety was a more prominent feature in Saudi residents. Noticeably increasing difficulty levels of exams can justify the fear of board examinations. Furthermore, frequent changes in the exam structure and dates lead to annoyance among trainees and confusion regarding the appropriate study methods. It is the responsibility of the teaching staff to familiarize the trainees with their exams. Exam-like activities help residents perform better in the actual exam. Canadian educators are more active than Saudi educators in terms of conducting mock exams for residents. The perceived disparity between exam scores and actual resident competency indicates the limited effectiveness of the current exam system as an evaluation instrument. Favoring multiple-choice questions as pretest reading material is a widespread practice among residents. Multiple-choice question-based written exams exaggerate this phenomenon to an extent that exam-driven reading compromises trainees' practice-related reading.

The number of trainees should fall within the capacity of a training program. As the annual acceptance rate of new residents increases and the residents' success rate declines, the overall number of enrolled trainees increases dramatically. In other words, overcrowded training programs lead to poor education, less surgical exposure, and lower competency. Flint et $\mathrm{al}^{12}$ demonstrated the relationship between the mentorship effect and high satisfaction rate with a training program. The lower satisfaction rate recorded in the Saudi training program may be attributed to the absence of mentorship or the wasteful use of the residents' valuable time when it is spent serving unprofessional consultants. Furthermore, Saudi board-eligible trainees showed lower self-confidence to perform standard orthopedic operations without senior supervision, which indicates inadequate surgical exposure. Therefore, the surgical logbook should be reformulated in a way that ensures sufficient surgical training in basic orthopedic procedures for each resident. ${ }^{19}$

Some limitations were encountered during the survey. The size of the Canadian sample was small and the researchers distributed the questionnaires manually. It was difficult to invite more participants using email because we had no access to the Canadian residents' email addresses; nevertheless, the Canadian sample can be considered to be representative. Demographic characteristics and training levels of the participants were comparable in both samples, with no significant confounders. Although general analysis of the residents' educational resources was performed in the present study, Internet-based learning was not specifically addressed. Other factors that may have impacted residents' education, such as workload, duty system, research, conferences, workshops, and surgical laboratory sessions, were not investigated. However, the present study contains novel explorations of various concerning aspects of the Saudi Orthopedic Residency Program 
and helpful comparisons with a different, well-established training program in Canada.

\section{Conclusion}

The primary aims of orthopedic training programs are to produce competent orthopedic surgeons who are knowledgeable, able to care for patients in a professional manner, technically skillful, good communicators, and highly competent educators. Guidelines and regulations are formulated and implemented in many countries to achieve these objectives. In fact, the Saudi Orthopedic Residency Program forces the pace toward high quality levels. However, current regulations are relatively vague. Although it would not be easy to revise the system, mandatory changes should be made promptly. In summary, we highly recommend addressing the following points in the Saudi Orthopedic Residency Program agenda:

1. Free electronic access to educational references and reputable orthopedic journals should be provided to all residents.

2. The philosophy of mentorship should be implemented to ensure that each resident achieves the requirements.

3. The function of resident, Fellow, and attending physician should be delineated clearly to ensure equitable distribution of residents' duties.

4. Turning a blind eye toward the residents' feedback about their trainers must be stopped as soon as possible, because residents represent the heart of the program.

5. Inactive, careless trainers should be identified and removed from their roles.

6. A logbook recording residents' surgical experience should be implemented as a measure of reaching surgical training targets.

7. The total number of enrolled trainees should be kept within the program's training capacity.

\section{Disclosure}

The authors report no conflicts of interest in this work.

\section{References}

1. Brian RW, Carla LB. How orthopaedic residents perceive educational resources. Iowa Orthop J. 2013;33:185-190.
2. McGill University Division of Orthopaedic Surgery Residency Program [webpage on the Internet]. Available from: http://www.mcgill.ca/ orthopaedics/residency-program. Accessed August 20, 2014.

3. Royal College of Physicians and Surgeons of Canada. CanMEDS: better standards, better physicians, better care [webpage on the Internet]. Available from: http://www.royalcollege.ca/portal/page/portal/rc/ resources/aboutcanmeds. Accessed August 20, 2014.

4. American Board of Medical Specialties. MOC competencies and criteria [webpage on the Internet]. Available from: http://www.abms. org/Maintenance_of_Certification/MOC_competencies.aspx. Accessed August 20, 2014.

5. Egol KA, Dirschl DR, Levine WN, Zukerman JD. Orthopaedic residency education: a practical guide to selection, training, and education. Instr Course Lect. 2013;62:553-564.

6. Marker DR, LaPorte DM, Seyler TM, et al. Orthopaedic journal publications and their role in the preparation for the orthopaedic in-training examination. J Bone Joint Surg Am. 2009;91(Suppl 6):S59-S66.

7. Confederation of Postgraduate Medical Education Councils. Australian Curriculum Framework for Junior Doctors (ACF) [webpage on the Internet]. Available from: http://www.cpmec.org.au/Page/ australian-curriculum-framework-for-junior-doctors-acf-menu. Accessed August 20, 2014.

8. Berkenbosch L, Schoenmaker SG, Ahern S, et al. Medical residents' perceptions of their competencies and training needs in health care management: an international comparison. BMC Med Educ. 2013;13:25.

9. Evaniew N, Holt G, Kreuger S, et al. The orthopaedic in-training examination: perspectives of program directors and residents from the United States and Canada. J Surg Educ. 2013;40:528-536.

10. Miyamoto RG Jr, Klein GR, Walsh M, Zukerman JD. Orthopedic surgery residents' study habits and performance on the orthopedic in-training examination. Am J Orthop (Belle Mead NJ). 2007;36(12): E185-E188.

11. LaPorte DM, Marker DR, Seyler TM, Mont MA, Frassica FJ. Educational resources for the orthopedic in-training examination. J Surg Educ. 2010;67(3):135-138.

12. Flint JH, Jahangir A, Browner BD, Mehta S. The value of mentorship in orthopaedic surgery resident education: the residents' perspective. J Bone Joint Surg Am. 2009;91:1017-1022.

13. Scolaro JA, Namdari S, Levin LS. The value of an annual educational retreat in the orthopedic residency training program. J Surg Educ. 2013;70(1):164-167.

14. Pinney SJ, Mehta S, Pratt DD, et al. Orthopaedic surgeons as educators applying the principles of adult education to teaching orthopaedic residents. J Bone Joint Surg Am. 2007;89:1385-1389.

15. Robbins L, Bostrom M, Craig E, Sculco TP. Proposals for change in orthopaedic education: recommendations from an orthopaedic residency directors' peer forum. J Bone Joint Surg Am. 2010;92: 245-249.

16. Bernstein J. Orthopaedic residency: how do you know when the "cake is done?". Clin Orthop Relat Res. 2013;471(1):9-12.

17. Gross RH, Greene J, Haynes R, Schafer MF. AOA symposium. Orthopaedic residency training: are we meeting expectations? J Bone Joint Surg Am. 2008;90(2):429-437.

18. Zukerman JD, Holder JP, Mercuri JJ, Phillips DP, Egol KA. Teaching professionalism in orthopaedic surgery residency programs. $J$ Bone Joint Surg Am. 2012;18;94(8):e51.

19. Salazar D, Schiff A, Mitchell E, Hopkinson W. Variability in Accreditation Council for Graduate Medical Education Resident Case Log System practices among orthopaedic surgery residents. J Bone Joint Surg Am. 2014;5;96(3):e22. 
Advances in Medical Education and Practice

Dovepress

\section{Publish your work in this journal}

Advances in Medical Education and Practice is an international, peerreviewed, open access journal that aims to present and publish research on Medical Education covering medical, dental, nursing and allied health care professional education. The journal covers undergraduate education, postgraduate training and continuing medical education including emerging trends and innovative models linking education, research, and health care services. The manuscript management system is completely online and includes a very quick and fair peer-review system. Visit http://www.dovepress.com/testimonials.php to read real quotes from published authors.

Submit your manuscript here: http://www.dovepress.com/advances-in-medical-education-and-practice-journal 